\title{
Autopsy based one year prospective study of death due to hanging
}

\author{
Mohit Shrivastava1, P.S. Thakur ${ }^{2}$, Devesh Pateria ${ }^{3, *}$ B. K. Singh ${ }^{4}$, Sunil K. Soni ${ }^{5}$ \\ ${ }^{1,3}$ P.G. Resident, ${ }^{2}$ Professor and Head, ${ }^{4}$ Associate Professor, ${ }^{5}$ Assistant Professor, Dept. of Forensic Medicine \& Toxicology, M.G.M. \\ Medical College \& M.Y. Hospital, Indore, Madhya Pradesh, India
}

*Corresponding Author: Devesh Pateria

Email:drdivsy@gmail.com

\begin{abstract}
Amongst all form of asphyxial death, hanging is most frequently encountered by forensic experts. Easy availability and presence of wide range of ligature materials at home itself makes hanging a preferred method of committing suicide over other methods. Findings over neck vary from case to case depending upon various factors like position of knot over neck, composition of ligature material, duration of suspension etc. The present prospective study was carried out in the Department of Forensic Medicine \& Toxicology, M.G.M. Medical College \& M.Y. Hospital, Indore, during the period from 1st August 2017 to 31st July 2018 and includes a total of 203 cases of death due to Hanging, brought to the mortuary of the hospital for medico-legal postmortem examination. Male victims were 137 (67.5\%) and females were $66(32.5 \%)$. The majority of victims belonged to 3rd decade among males were $49(24.1 \%)$, followed by 4 th decade were 44 ( $21.7 \%)$ while 2nd decade was most common among females were $25(12.3 \%)$, followed by 3rd decade were $24(11.8 \%)$. The objective of the study was to understand various demographic profile and various aspects of deaths due to hanging so as to suggest some remedial measures.
\end{abstract}

Keywords: Hanging, Ligature Material, Position of knot, Suicide, Place of hanging.

\section{Introduction}

Hanging is that form of asphyxia which is caused by suspension of the body by a ligature which encircles the neck, the constricting force being the weight of the body. ${ }^{1}$ Sometimes, hanging is adopted as a last resort after other forms of suicide (poisoning, cut throat injury, etc.) have failed to produce the desired effect. The thought to hang one-self may come progressively or on an impulse. ${ }^{2}$

The first symptom is the loss of power and subjective sensations, such as flashes of light and ringing in the ears, followed by loss of consciousness, which is so rapid that hanging is regarded as a painless form of death. ${ }^{3}$

The World Health Organization (WHO) estimates that of the nearly 900,000 people who die from suicide globally every year, 170,000 are from India. ${ }^{4}$ However, India's National Crime Records Bureau (NCRB) - which report official suicide rates based on police reports - estimated only 135,000 suicides in $2011 .^{5,6}$

The number of suicides in India during the decade (2005-2015) has recorded an increase of $17.3 \%(1,33,623$ in 2015 from 1,13,914 in 2005). The no. of cases were reported Madhya Pradesh (10,293 suicides) accounted for $7.7 \%$ of the total suicides reported in India. ${ }^{7}$ Hanging is invariably suicidal. Accidental and homicidal hangings are rare. ${ }^{8}$

\section{Materials and Methods}

The present prospective study was carried out in the Department of Forensic Medicine \& Toxicology, M.G.M. Medical College \& M.Y. Hospital, Indore (M.P.) during the period from 1st August 2017 to 31st July 2018 and analysis a total of 203 cases of death due to Hanging, brought to the mortuary of the hospital for medico-legal postmortem examination.

Details of the cases were collected like age, sex, residence, place of hanging, month wise distribution of the cases from the police papers, the inquest reports, hospital records and findings during autopsy like position of knot, type of ligature material and P.M. findings, etc. The information was compiled, tabulated and analyzed.

\section{Observations and Results}

It is observed that, out of 2197 medico legal post mortem cases conducted to the Dept. of Forensic medicine $\&$ toxicology, 203 were cases of hanging. Incidence was $9.2 \%$. During this study it is observed that there were male predominance with 137 (67.5\%) cases out of 203 cases of hanging and female victims were only $66(32.5 \%)$ cases. [Fig. 1]

The maximum numbers of hanging 49 [24.1\%] cases were observed between age group of 21-30 years in males and 25 [12.3\%] cases were observed between age group of 11-20 years in female. In age below 10 years not any single case was reported and in old age above 61 years only 4 [1.9\%] cases were found. The most vulnerable age group for hanging was observed as 11-40 years in which 168 [82.7\%] cases was reported. This particular age group is most active period in one's life. Frustration due to various reasons such as financial problems, the burden of livelihood, unemployment, and poverty contributed to their death. [Fig. 2]

Highest numbers of 141[69.5\%] victims were from urban. Low incidence 62 [30.5\%] in rural area due to less rural population as most of young individual migrate to cities for study, for seeking job and to achieve modern lifestyle they become frustrated early and commits such an lethal offence. [Fig. 3]

In the present study, among total number of cases the most preferred places chose for hanging was in closed 194 [95.5\%] cases to increase the success rate as victims usually find the place when there was nobody present nearby 
him/her like closed room, toilet, house, shop, office, etc. which will suit his purpose of committing suicide. [Fig. 4]

Typical hanging was observed only in 25 [12.3\%] cases in which position of knot was found behind the neck in occiput region, while atypical hanging in which position knot present either on right or left side of neck was reported in 147 [72.4\%] cases. In 31 [15.2\%] cases position of knot was not found appreciable. [Table 1]

During present study, the ligature material was found in situ in only 106 [52.3\%] cases in which nylon rope was found maximum in 32 [15.7] cases followed by jute rope in 21 [10.3\%] cases, this shows that in maximum number of cases the easy available and cheap materials like rope, cotton rope, synthetic saree were used to commit suicide. [Table 2]

When month wise distribution of cases was analyzed, no any specific trend was observed but the highest incidences of hanging cases were reported in summer season [Fig. 5]

Postmortem Findings: Petechial hemorrhages (sub conjunctival hemorrhage) were seen in the 45 [22.1\%] cases. Body showed post mortem lividity in the legs in 40 [19.7\%] cases. This depends mostly on the duration of suspension of the body and nature of the ligature materials used and also the time elapsed between death and autopsy. [Table 3]

Bluish discoloration of nails/lips/earlobes was the most common finding observed in $156(76.8 \%)$ cases. Protrusion of tongue was seen in 115 [56.6\%] cases. The probable reason for this phenomenon could be that the constricting force of the ligature caused upward pressure on the neck structure causing elevation of the tongue. [Table 3]

Salivary stain was present in 53 [26.1\%] cases of hanging. Saliva is often found dribbling from angle of the mouth down the chin. This is supposed to be sure sign of ante mortem hanging as secretion of saliva being a vital function, cannot occur after death. Hyoid bone fracture was not found in any such cases of hanging. In our study, majority of victims were of young age below 40 years, and the frequency of fracture of hyoid bone was found increased with age as it got ossified. [Table 3]

Table 1: Position of knot

\begin{tabular}{|c|c|c|c|}
\hline Occiput (\%) & Right side of neck (\%) & Left side of neck (\%) & Not Appriciable (\%) \\
\hline $25(12.3 \%)$ & $79(38.9 \%)$ & $68(33.5 \%)$ & $31(15.2 \%)$ \\
\hline
\end{tabular}

Table 2: Type of ligature material

\begin{tabular}{|l|c|c|}
\hline \multicolumn{1}{|c|}{ Ligature Material } & Number of cases & Percentage (\%) \\
\hline Cotton Dhoti & 5 & $2.4 \%$ \\
\hline Cotton Dupatta & 8 & $3.9 \%$ \\
\hline Cotton rope & 18 & $8.8 \%$ \\
\hline Cotton Gamchha & 4 & $1.9 \%$ \\
\hline Synthetic saree & 16 & $7.8 \%$ \\
\hline Nylon rope & 32 & $15.7 \%$ \\
\hline Jute rope & 21 & $10.3 \%$ \\
\hline ELECTRIC WIRE & 2 & $0.9 \%$ \\
\hline NA & 97 & $47.7 \%$ \\
\hline Total & 203 & $100 \%$ \\
\hline
\end{tabular}

Table 3: Post mortem examination findings

\begin{tabular}{|l|c|c|}
\hline \multicolumn{1}{|c|}{ Findings } & Number of cases & Percentage (\%) \\
\hline Sub conjunctival hemorrhage & 45 & $22.1 \%$ \\
\hline Protrusion of tongue & 115 & $56.6 \%$ \\
\hline Salivary Stain & 53 & $26.1 \%$ \\
\hline Ear/ Nose/ Mouth bleed & 25 & $12.3 \%$ \\
\hline Bluish discoloration of nails/ lips/ear lobes & 156 & $76.8 \%$ \\
\hline Post mortem lividity over lower limb & 40 & $19.7 \%$ \\
\hline Semen ejaculation & 70 & $34.4 \%$ \\
\hline Fecal matter passed off & 34 & $16.7 \%$ \\
\hline Feet planter flexed & 48 & $23.6 \%$ \\
\hline Patechial hemorrhage over scalps & 23 & $11.3 \%$ \\
\hline
\end{tabular}




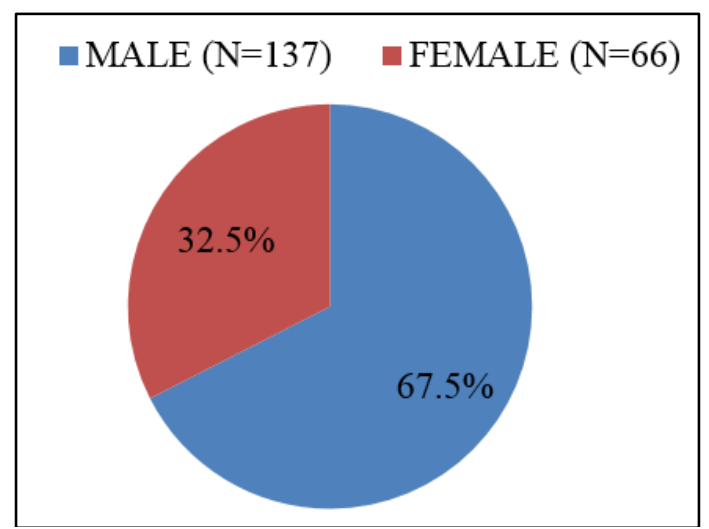

Fig. 1: Gender wise distribution $(\mathrm{N}=\mathbf{2 0 3})$

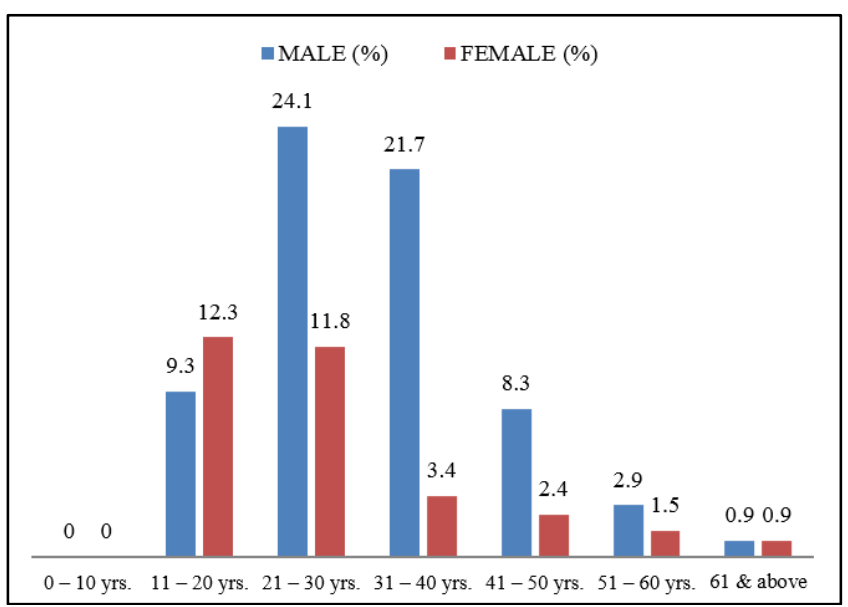

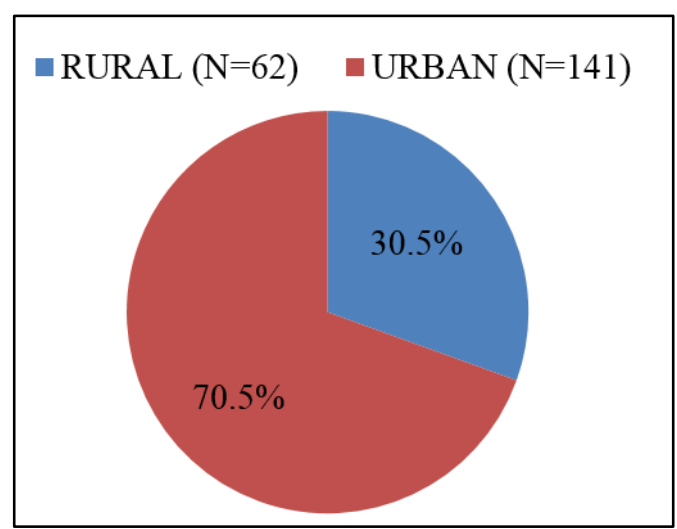

Fig. 3: Residence $(\mathrm{N}=\mathbf{2 0 3})$

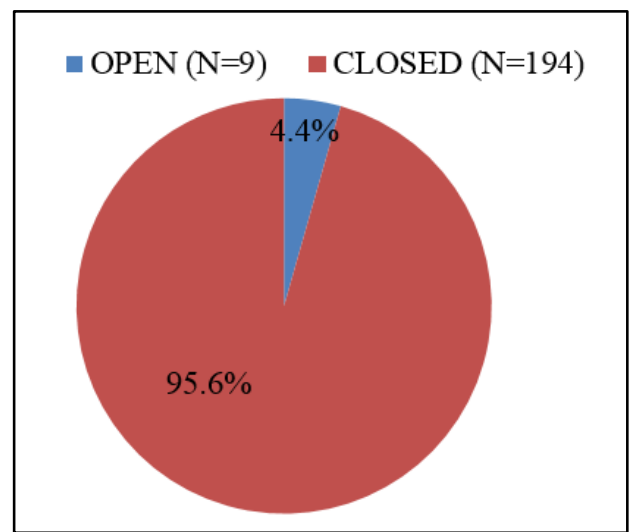

Fig. 4: Place of hanging $(\mathrm{N}=203)$

Fig. 2: Age and sex wise distribution of cases $(\mathrm{N}=203)$

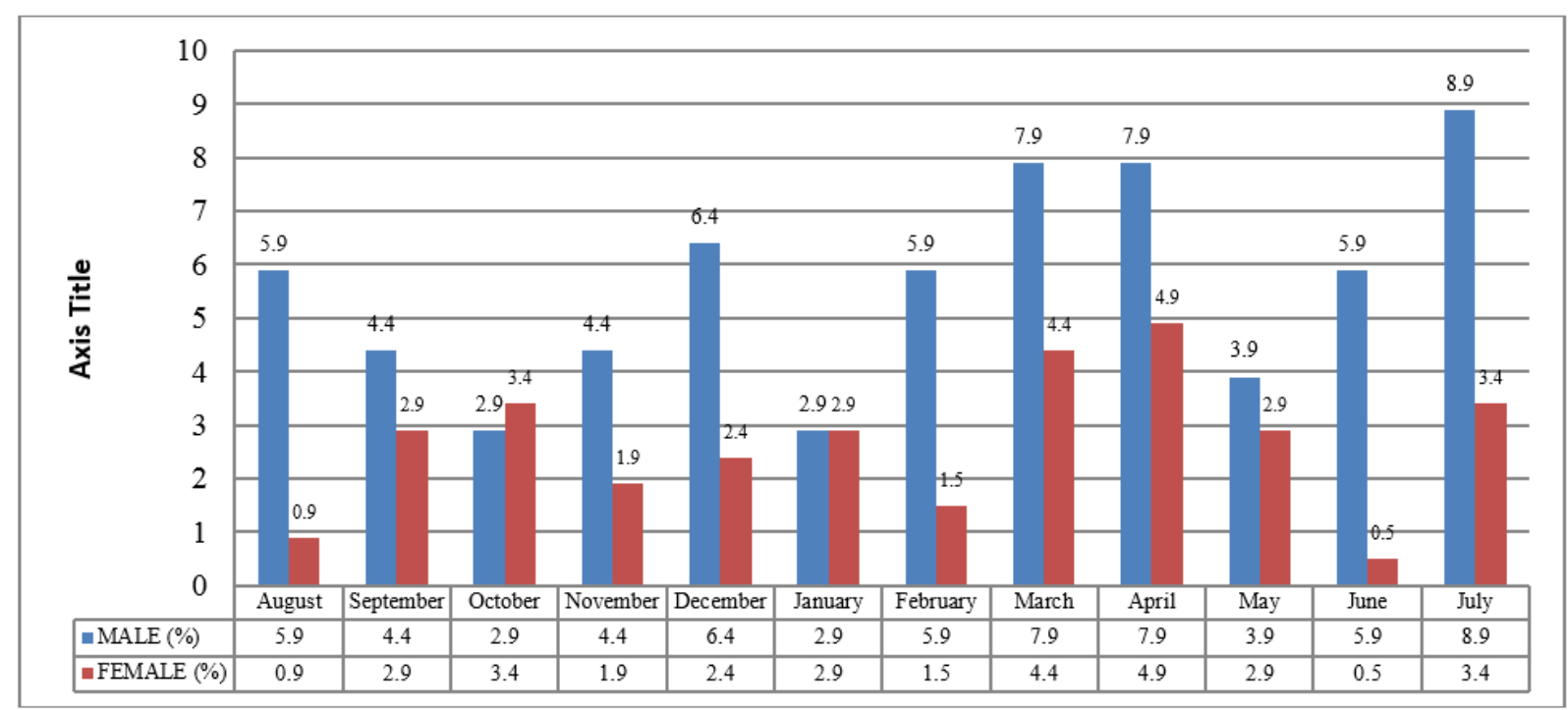

Fig. 5: Month wise distribution of cases

\section{Discussion}

The present prospective study was carried out in the Department of Forensic Medicine \& Toxicology, M.G.M. Medical College \& M.Y. Hospital, Indore (M.P.) during the period from 1st August 2017 to 31st July 2018. It has been compared with other similar studies carried out in different parts of the world to bring out the similarities and differences.

In the present study, the total number of hanging cases conducted were 203 [9.2\%], almost similar cases was observed by Manoj K Baishya et al, ${ }^{9}$ less number of cases was observed by N.Vijaykumari, ${ }^{10}$ Patel A P et al ${ }^{11}$ observed 332 cases of hanging in their study period. 
Majority of deaths due to hanging were males [67.5\%] with male: female ratio 2:1. Similar findings were observed by other authors Manoj K Baishya et al, ${ }^{9}$ K.M. Pathak et al ${ }^{12}$ and differ from SH Bhosle et al. ${ }^{13}$

The highest number of cases of death due to hanging in males were in the age group of 21-30 years [24.1\%] while in females it was 11-20 years [12.3\%]. Similar to study conducted by S.H. Bhosle et al, ${ }^{13}$ G.K. Bharath et al ${ }^{14}$ and differ from study conducted by N.Vijaykumari. ${ }^{10}$

In present study, the most commonly used ligature materials were nylon rope in 32 [15.7] cases, consistent with findings of N. Vijaykumari ${ }^{10}$ and Modi. ${ }^{15}$ In another study done by Ahmad M. ${ }^{16}$ and B.R. Sharma et al. ${ }^{17}$ dupatta was the commonly used ligature material by females, whereas saree was used by males.

On eliciting the detailed history from the police and relatives of the deceased, we came to know the fact that majority of the victims [95.5\%] were recovered from closed areas that is mostly at home or work place, similar with the study conducted by Patel A P et al, ${ }^{11} \mathrm{P}$. N Murkey et $\mathrm{al}^{18}$ and Sharija et al. ${ }^{19}$

Highest numbers of victims were from urban region i.e., $69.5 \%$, while $30.5 \%$ were from rural area. Similar findings were observed by Manoj $\mathrm{K}$ Baishya et $\mathrm{al}^{9}$ and differ from author Tripude B.et $\mathrm{al}^{\mathbf{2 0}}$ and Samantha AK. et al. $^{21}$

In present study position of the knot in a majority of cases was found present in right and left side of neck 38.9\% and 33.5\% respectively [atypical hanging]. Similar findings were observed by Manoj K Baishya et $\mathrm{al}^{9}$ and differ from Mishra P.K. et al. ${ }^{22}$

In the present study, salivary stain mark was present in $26.1 \%$ cases, Soumya R. Nayak et $\mathrm{al}^{23}$ found dribbling of saliva in $16.4 \%$ cases, while Mohammed M. Sheikh et $\mathrm{al}^{24}$ observed in $38.37 \%$ cases. Our findings are not consistent with Modi. ${ }^{15}$

In our study, we also compiled the month wise distribution of cases and came to know that there was no month wise specific variation observed, but highest incidences of hanging cases were reported in summer season.

\section{Conclusion}

In the present study Males of younger age group in majority have committed suicide by hanging in closed space, preferred place was at home. Salivary stain mark, which is considered a hallmark of ante-mortem hanging, was present only in $26.1 \%$ cases. No case of hyoid bone or thyroid cartilage fracture was found.

Suicide today has become a major health issue throughout the world, despite all legal, moral, social and religious barriers. Psychiatric counseling should be given to everyone in all age groups of both the sexes. Males of younger age group were mostly involved in the study. Other family members should keep a constant watch on the affected member of family and should try to engage them in continuous talks.
A study on common methods of suicide, risk factors, socio-demographic factors, cultural aspects and other established etiologies in an area serve as road map not only for a forensic expert but also for local governing bodies to take appropriate control measures. This study is meant to conclude the above Perspective. In future prospective study can be conducted including psychological autopsy for extended in depth study which can be helpful for the society and aiming towards reducing such untimely and unfortunate incidences.

\section{Conflict of Interest: Nil.}

\section{References}

1. Reddy K.S.N. Mechanical Asphyxia', The Essentials of Forensic Medicine and Toxicology, 2017, 34th ed, p315.

2. Mallikarjun S Ballur, Dayananda R, S. K. Karthik, Priyanka Murgod, G Sujathan. 'Study of Ligature Mark in hanging cases in Bangalore East Region. J Indian Acad Forensic Med. 2016;38(1) ISSN 0971-0973

3. Modi JP. A Textbook of Medical Jurisprudence and Toxicology, $25^{\text {th }}$ ed, $\mathrm{p} 493$.

4. World Health Organization. The Global Burden of Disease: 2004 update. Geneva: WHO; 2008.

5. National Crime Records Bureau. Accidental Deaths and Suicide in India. New Delhi: Government of India; 2011.

6. National Crime Records Bureau. Accidental Deaths and Suicides in India. New Delhi: Government of India; 2008.

7. National Crime Records Bureau. Accidental Deaths and Suicides in India. New Delhi: Government of India; 2015.

8. Pillai V. V. Textbook of Forensic medicine \& Toxicology, 17th ed, p310.

9. Baishya Manoj K, Mahanta Putul. An Epidemiological Study of Hanging Cases Brought to the Gandhi Medical College and Hospital for Medicolegal Autopsy- A Retrospective Study. Medico-legal Update. 2014;14(2):128-129.

10. N. Vijayakumari Suicidal Hanging: A Prospective Study. $J$ Indian Acad Forensic Med. 2011;33(4):353-355.

11. Patel A P. Study of Hanging Cases in Ahmedabad Region. $J$ Indian Acad Forensic Med. 2012;34(4):342-345

12. Pathak Manoj K, Kumar Awdhesh. An Epidemiological and Medicolegal Study of Violent Asphyxial Death at Varanasi, India. Medicolegal Update. 2014;14(2):93-94.

13. SH Bhosle, 'Violent asphyxial death due to hanging: a prospective study. J Forensic Med, Sci Law. 2014;23(1).

14. G.K. Bharath et al Profile and Pattern of Hanging Cases at a Tertiary Care Hospital, Khammam; Telangana Indian Acad Forensic Med. January- March 2016, Vol. 38, No. 1 p67-71

15. Modi JP. A Textbook of Medical Jurisprudence and Toxicology.24th Ed. Nagpur, Butterworths Wadhwa; 2012: p445-51.

16. Ahmad M, Hossain MZ. Hanging as a method of suicideretrospective analysis of postmortem cases. JAFMC Bangladesh. 2010;6(2):37-39.

17. Sharma BR, Harish D, Anup Sharma, Swati Sharma, Harshabad Singh. Injuries to neck structures in deaths due to constriction of neck, with a special reference to hanging. $J$ Forensic Leg Med. 2008;15:298-305.

18. Murkey P. N, Ambedkar Ranjan, Tirpude B. H, Khan Sharjeel, Khandekar I. L, Zopate Pravin, Bhagwat Deepak, Ramteke Rahul. Autopsy Based Cases of Hanging with Respect to Material Status and Place of Hanging at Tertiary Care Centre in Central India. Indian J of Forensic and Community Med. 2017;4(1):64-67. 
19. Sharija S, Shreekumari K, Geetha O. Epidemiological Profile of Hanging in Southern part of Kerala: An Autopsy Based Study. J Indian Acad Forensic Med. 2011;33(3):237-240.

20. Tripude B. H, Murkey. P N, Pawarvg, Shende S.A. Profile of hanging cases on Autopsy at a tertiary care Hospital in central India. JKMLS. 2010;19(2):3-7.

21. Samantha AK, Nayak SR. Newer trends in Hanging Deaths. $J$ Indian Acad Forensic Med. 2012;34:37-39.

22. Mishra P.K. Profile of Deaths Due to Hanging- An autopsy based Retrospective Study at a Tertiary Care Centre in Indore. IJFCM. 2018;5(1):34-38.

23. Nayak Soumya R, Naik Subal K., Samanta Ashok K., Jena Manoj K. Analysis of Profile of Hanging Deaths in Coastal Odisha. J Indian Acad Forensic Med. 2017;39(1):16-18.
24. Sheikh Mohammed Musaib M, Chotaliya H. J, Modi A. D, Parmar A. D, Kalele S. D. A Study of Gross Postmortem Findings in Cases of Hanging and Ligature Strangulation. $J$ Indian Acad Forensic Med. 2013;35(1):63-65.

How to cite this article: Shrivastava M, Thakur P.S, Pateria D, Singh B. K, Soni S. K. Autopsy based one year prospective study of death due to hanging. Indian $\mathrm{J}$ Forensic Community Med. 2018;5(4):240-244. 